\title{
LA EVOLUCIÓN INSTITUCIONAL DEL DESPIDO EN ESPAÑA: UNA INTERPRETACIÓN EN TÉRMINOS DE UN ACCIDENTE HISTÓRICO*
}

MIGUEL ÁNGEL MALO

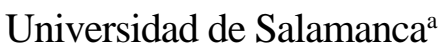

\section{RESUMEN}

En este artículo se realiza un análisis de la evolución institucional del despido en España. Se explica cómo determinados accidentes históricos que han generado dependencia del pasado dieron lugar a un sistema de despido libre costoso y los incentivos de empresas, trabajadores y gobiernos para sostener dicho sistema. Se analizan las ineficiencias de este sistema: incremento sustancial del coste del despido, uso distorsionado de las causas de despido y dificultades para hacer frente a grandes shocks económicos generalizados. Por último, se explica cómo la reforma de las prestaciones por desempleo de 2002 es la culminación de dicho sistema de despido libre costoso.

\footnotetext{
${ }^{*}$ Una versión previa de este trabajo se expuso en un seminario de la Universidad de Salamanca, donde los asistentes realizaron comentarios y sugerencias que han resultado muy útiles. No obstante, quisiera agradecer en particular a Santiago López y Ricardo Robledo los comentarios realizados en dicho seminario y en conversaciones posteriores. También recibí comentarios y sugerencias útiles en la presentación de este trabajo en las IX Jornadas de Economía Crítica, celebradas en Madrid en marzo de 2004. Agradezco también los comentarios y críticas realizados por tres evaluadores anónimos, que han colaborado sustancialmente en la mejora de esta investigación. Obviamente, sólo el autor es responsable de los errores y problemas que pudieran existir en este trabajo. Esta investigación se ha desarrollado con financiación de la CICYT (proyecto SEC2001-0061).

${ }^{a}$ Departamento de Economía e Historia Económica, Universidad de Salamanca, Campus Miguel de Unamuno, Edificio FES (E-37007 Salamanca). malo@usal.es
} 
Palabras clave: despido disciplinario, accidente histórico, despido libre, dependencia del pasado, Derecho Laboral

\begin{abstract}
In this article, we present an analysis of the institutional evolution of firing in Spain. We explain how a certain path-dependence has been created by historical accidents and how this is the mechanism behind the current system of a costly employment at will. The incentives of firms, workers and governments to sustain such a system are also discussed. We show the main inefficiencies of the system: a substantial increase in severance pay, a distorted use of the legal framework, and limitations to give a rapid answer to a big negative shock. Finally, we discuss how the unemployment benefits reform of 2002 can be understood as the culmination of Spain's policy of costly employment at will.
\end{abstract}

Keywords: disciplinary dismissal, historical accident, employment at will, pathdependence, Labour Law

JEL Classification: N34, N44, K31, J63, J53

\title{
1. INTRODUCCIÓN
}

¿De dónde proviene el actual sistema español de despido? ¿Por qué el despido disciplinario se ha convertido en la figura principal de dicho sistema y la indemnización de 45 días de salario por año trabajado en la referencia para el coste del despido? Este artículo tiene como objetivo intentar proporcionar respuestas a dichas preguntas mediante un análisis de la evolución institucional de la regulación del despido. Para ello se seguirá la propuesta de North (1990) para entender el cambio institucional, la cual enfatiza la pervivencia de sistemas institucionales ineficientes y la importancia crucial de los accidentes históricos que generan «dependencia del pasado» (path-dependence).

La consideración conjunta de los aspectos económicos, jurídicos e históricos nos llevará a una interpretación de la normativa sobre despidos más amplia y más rica que la convencional. Dicha interpretación convencional de la evolución histórica del despido y sus costes en España -cuya mejor representación es probablemente Serrano y Malo de Molina (1979)- afirma que con el inicio de la dictadura franquista se crea un sistema de relaciones laborales que descansa sobre la seguridad en el empleo para los trabajadores como contrapeso de la flexibilidad salarial. La forma legal de dicha seguridad habría sido la creación de costosos procedimientos legales pensados para dificultar la realización de despidos. Tras la 
crisis de finales de los cincuenta y la puesta en marcha del Plan de Estabilización de 1959, el sistema de relaciones laborales franquista habría entrado en una nueva etapa que seguiría marcada por un fuerte intervencionismo estatal, con sustanciales restricciones legales al despido -económico y disciplinario-, pero con una gran importancia de los componentes variables de la retribución salarial. Las consecuencias de estas características fueron flexibilidad salarial y rigidez en el ajuste vía cantidades, es decir, en los despidos.

Por el contrario, el sistema de relaciones laborales que, tras diversos cambios legales, se instaura a partir de 1980 con el Estatuto de los Trabajadores como pieza fundamental habría tenido, frente al anterior, dos consecuencias diferentes: rigidez salarial -por el libre juego de la negociación colectiva- y una mayor flexibilidad -en relación con la situación previa- en los despidos.

Sin poner en cuestión la tesis de una mayor flexibilidad salarial en el sistema de relaciones laborales franquista -documentada, por ejemplo, en Malo de Molina (1983 y 1984)-, veremos aquí cómo la normativa del despido tenía una rigidez más formal que práctica y que, de hecho, no tenía un carácter de contrapeso de una estructura salarial flexible. Por el contrario, veremos que más bien el sistema clásico de despido tuvo una aparición histórica que responde a los problemas del final de periodo autárquico y al intento de dar una vía de ajuste a las empresas en aquel momento. Esto llevó a la creación de hecho del despido libre costoso, el cual no ha hecho más que consolidarse a lo largo del tiempo, incluso hasta el decreto de reforma de las prestaciones por desempleo de mayo de 2002. Argumentos en esta línea ya se habían expuesto con anterioridad en la literatura jurídica: por ejemplo, por Rodríguez Fernández (1989). La novedad de este trabajo consiste en desarrollar el argumento de una forma mucho más amplia -incardinándolo en una historia del despido- y en las argumentaciones de historia económica, que nos permiten analizar desde la misma perspectiva incluso los cambios más recientes de la normativa laboral española concerniente al despido y sus costes.

El desarrollo del artículo tiene la siguiente estructura. En primer lugar, se realiza en el apartado 2 una presentación de la estructura conceptual, siguiendo a North (1990), que servirá para interpretar la evolución institucional del despido. En el apartado 3 se explica la utilización de los distintos tipos de despido para reducir plantilla, mostrando los fuertes incentivos para el uso del despido disciplinario por parte de las empresas para hacer frente a los shocks negativos. En el 4 se presenta la historia de la regulación del despido disciplinario, mostrando que siempre se pudo despedir fácilmente bajo el sistema de relaciones laborales franquista, pero de forma costosa -y eso era lo que lo volvía difícil-, gracias a la figura del incidente de no readmisión, destacando la importancia del accidente histórico que dio lugar al incidente de no readmisión y cómo ha generado dependencia del pasado, debido a los incentivos que proporciona a trabajadores, empresarios y gobiernos. En la conclusión se resumen las principales aportaciones 
del artículo y cómo la interpretación que aquí se presenta del sistema de despido español puede ayudar a entender los cambios introducidos en la normativa en 2002, que alteran la percepción de la indemnización por despido improcedente y el pago de los salarios de tramitación.

\section{EL CAMBIO INSTITUCIONAL: ACCIDENTES HISTÓRICOS Y DEPENDENCIA DEL PASADO}

A partir del trabajo ya clásico de David (1985) sobre la dependencia del pasado en el desarrollo y aplicación de la tecnología, North (1990) trata de explicar el mantenimiento a lo largo del tiempo de sistemas institucionales ineficientes.

¿Cómo es posible la pervivencia de instituciones ineficientes en términos evolutivos? ¿Por qué algunas sociedades sencillamente no imitan las instituciones de otras sociedades que se han mostrado como más eficientes?

Dos aspectos cruciales para dar respuesta a estas preguntas son: rendimientos crecientes y mercados imperfectos caracterizados por costes de transacción significativos. Según North (1990, cap. 11) éstas son las dos fuerzas que configuran el cambio institucional -y que, además, dan sentido a la existencia de instituciones.

Hay unos costes iniciales de puesta en marcha elevados cuando las instituciones son creadas ex novo. Aparecen así efectos de aprendizaje muy relevantes para los agentes -en nuestro caso, empresas y trabajadores. La razón de su aparición es el nuevo conjunto de oportunidades factibles proporcionado por las instituciones. Los agentes -en especial las empresas, porque son las que toman las decisiones sobre cuándo y cómo despedir- se adaptarán para tomar ventajas de las nuevas oportunidades generadas por el nuevo marco institucional, lo cual no implica necesariamente que esta adaptación resultará en un incremento de la eficiencia social. Se producirán efectos de coordinación (espontánea) en el comportamiento de los agentes, que se van reforzando a lo largo del tiempo. Las expectativas de adaptación se producen porque, conforme se desarrollan relaciones entre los agentes que interactúan en el marco institucional, irán desapareciendo las incertidumbres de la aplicación de la institución. De esta manera, la red de interdependencia que genera una institución produce enormes rendimientos crecientes.

Con rendimientos crecientes del tipo descrito, las instituciones son cruciales para entender el funcionamiento de largo plazo de la economía. No obstante, si los mercados fueran competitivos -o con costes de transacción despreciables-, el funcionamiento de largo plazo de la economía sería eficiente. Ahora bien, con mercados incompletos en los que el intercambio de información es deficiente y fragmentario y con costes de transacción relevantes pueden aparecer y prevale- 
cer sendas de largo plazo persistentemente ineficientes. Bajo estos supuestos, los agentes económicos tienen que realizar considerables esfuerzos -y dedicar recursos valiosos- a descifrar un entorno complejo con las construcciones mentales disponibles -ideas, teorías e ideologías-, reflejándose en resultados imperfectos y muchas veces con carácter de tanteo.

En nuestro caso, el procedimiento institucional para despedir sería eficiente si la competencia condujera a los agentes que intervienen en el proceso de despido a corregir el modelo y a instaurar unas nuevas instituciones de una sola vez. Sin embargo, las exigencias de la competencia en los mercados no crearán ese cambio de una sola vez, sino un cambio paulatino en el sistema de despido, que se analizará paso por paso en el apartado cuarto. La estructura conceptual propuesta por North nos lleva entonces a considerar que la historia importa para explicar cómo es el sistema de despido, y es precisamente cuando la historia importa que los accidentes históricos pueden generar dependencia del pasado. Bajo información incompleta, los cambios en el sistema de despido responderán más bien a necesidades específicas del momento histórico en que se producen -como es el caso del cambio introducido al final del periodo autárquico, que analizaremos en el apartado cuarto. Los rendimientos crecientes -asociados con el proceso de aprendizaje en el «uso» de la institución- hacen que, más adelante, la vuelta atrás o el cambio sean vistos como opciones inviables, más caras que el mantenimiento de los aspectos introducidos por necesidades de un momento histórico que han dejado de estar presentes. De esta manera, el accidente histórico prolonga sus efectos a lo largo del tiempo, generando «dependencia del pasado».

Veamos ahora cómo se aplicarían estas proposiciones a nuestro tema, la evolución institucional del despido en España.

En términos económicos, el despido está relacionado con la asignación de los factores de producción en el seno de la empresa. Pero la ley no suele otorgar al empresario una libertad total a la hora de asignar los factores de producción, especialmente el trabajo, en países con sistema legal de Derecho Civil, como es el caso de España y de la Europa Continental en general. Así, bajo los sistemas legales de Derecho Civil, el despido tiene un carácter de respuesta ante situaciones de fuerza mayor, que es lo que hace que sea aceptable romper la relación laboral indefinida. Sin embargo, esta fuerza mayor tiene que ver con la actividad habitual de la empresa, ya que las crisis que pueden motivar los despidos no tienen un carácter excepcional en la vida económica. Ésta es una importante asimetría de los contratos laborales respecto de otros tipos de contratos, y es uno de los aspectos que configura el Derecho Laboral como tutelar de la parte presuntamente más débil de la relación laboral, el trabajador. Esto es lo que genera la necesidad de regular las causas que permiten que la empresa rompa la relación laboral. La división tradicional de causas es: imputables al trabajador -sobre todo, disciplinarias- o imputables a la empresa -sobre todo, económicas. Ambos tipos de causas 
se regulan de manera distinta, con diferentes procedimientos y garantías. En un sistema de Derecho Civil, la normativa laboral aspira a prever todas las posibilidades de ajuste. Pero otra cuestión diferente es que esa normativa sea eficiente en el sentido de que proporcione el cauce adecuado para las salidas de trabajadores y con unos costes relativos de cada una de las vías de salida que fomenten el uso correcto de la normativa.

Los procedimientos de salida de la empresa durante el periodo autárquico -heredados del periodo republicano, pero adaptados a una lógica totalitaria- fueron imposibles de sostener, como una muestra más de la ineficiencia absoluta del sistema económico que se quiso instaurar tras la Guerra Civil. Tenemos en ese momento una situación típica en la que un entramado institucional es claramente ineficiente e impone cargas al sistema económico imposibles de sostener. Se abre así el camino para un cambio institucional que encaja en la interpretación clásica que del mismo hace, por ejemplo, Alchian (1950) sobre la inviabilidad de sistemas institucionales ineficientes, los cuales serían evolutivamente sustituidos por sistemas más eficientes.

Pero la forma que toma ese cambio está más en la línea propuesta por North (1990) sobre la pervivencia de sistemas institucionales parcialmente ineficientes debido a la aparición de fenómenos de dependencia del pasado. Como veremos, el cambio institucional clave sobre el despido tiene lugar al final de la autarquía, permitiendo de hecho el despido sin causa, pero asumiendo un cierto coste monetario. Este cambio no es la creación ex novo de un sistema nuevo para despedir. En realidad, es una solución de compromiso frente a las mejoras salariales que se habían dado como resultado de los problemas sociales derivados de la crisis del sistema autárquico. El incidente de no readmisión, aunque nace por necesidades de ese momento histórico particular, queda anclado dentro de la práctica jurídica española durante el siguiente medio siglo. Tiene una lógica económica clara: otorga a la empresa una vía para realizar despidos según le convenga y para eludir la necesidad de autorización administrativa que habría tenido que solicitar si hubiera alegado razones económicas, como se explicará con detalle más adelante. No obstante, esto no significa que sea un mecanismo institucional eficiente, ya que este sistema de despido arrastra características relacionadas con la formulación legal inicial: el coste del despido se establece en relación con el despido disciplinario improcedente y no de acuerdo con lo que se considera adecuado para un despido económico procedente. Esto genera una clara ineficiencia en el presente, ya que las indemnizaciones por despido económico procedente son más bajas en el Estatuto de los Trabajadores, 20 días de salario por año trabajado, menos de la mitad de los 45 establecidos para el disciplinario improcedente-, pero la normativa y su aplicación no generan incentivos para la utilización de la figura jurídica del despido económico, ya que el control de la causa económica es muy deficiente y, por tanto, generador de incertidumbres para las empresas. Estamos, pues, 
ante un fenómeno de dependencia del pasado en esta institución del mercado de trabajo, que hace que perviva una institución ineficiente, aunque menos ineficiente que el sistema existente en el periodo autárquico, que lo era tanto que se convertía en inviable.

\section{TIPOS DE CAUSAS PARA DESPEDIR Y TIPOS DE DESPIDO UTILIZADOS EN ESPAÑA}

Antes que nada, conviene explicar hasta qué punto el despido disciplinario ha devenido la figura jurídica principal para realizar despidos, y no lo han sido los tipos de despido pensados explícitamente para reducir plantilla ante situaciones económicas adversas. Esto nos permitirá entender por qué el análisis del despido disciplinario - en lugar de otros tipos de despido- nos proporcionará las claves para entender cómo se ha despedido y se despide en España.

Las causas del despido pueden ser de dos tipos: no imputables al trabajador -esto es, por necesidades de la actividad productiva- e imputables al trabajador. Esta distinción ha permanecido inalterada desde la Ley de Jurados Mixtos de 1931 hasta la actualidad. La crisis como causa de despido -el habitualmente denominado como despido económico- quedaría incluido en el grupo de las no imputables al trabajador. Por su parte, la causa disciplinaria estaría entre las imputables al trabajador.

Aparentemente, la distinción anterior nos obligaría a estudiar meramente los despidos colectivos - añadiendo, tras la reforma del Estatuto de los Trabajadores de 1994, los despidos objetivos por causas económicas-, como aquellos que están originados en verdaderos ajustes de plantilla que tratan de hacer frente a las oscilaciones del ciclo económico, mientras que los despidos individuales recogerían sobre todo los disciplinarios. Sin embargo, el Cuadro 1 muestra que el despido individual es la gran vía de ajuste de las empresas españolas. Los datos del Cuadro 1 cubren el periodo 1974-2003 y permiten apreciar que esta situación se producía tanto en los últimos años del sistema franquista de relaciones laborales como en el establecido a partir de la transición política y la democracia. Los despidos individuales respecto de los colectivos oscilan entre 8 veces más y 1,51 veces más ${ }^{1}$.

\footnotetext{
${ }^{1}$ Este valor mínimo corresponde a 1976, año en el que se introdujo una ley que eliminaba la posibilidad de pagar al trabajador una indemnización en caso de despido improcedente, imponiendo en caso de improcedencia la readmisión del trabajador, lo cual puede explicar este valor tan sumamente bajo de despidos individuales. Esto se explicará más detalladamente en el subapartado 4.3 .
} 


\section{CUADRO 1}

TRABAJADORES DESPEDIDOS EN DESPIDOS INDIVIDUALES Y EN DESPIDOS COLECTIVOS, 1974-2003

\begin{tabular}{|c|c|c|c|c|c|c|}
\hline Año & D. Individuales & D. Colectivos & DI/DC & DI/Asal. (\%) & DC/Asal. (\%) & $\Delta$ PIB (\%) \\
\hline 1974 & 157.691 & 25.590 & 6,16 & 1,83 & 0,30 & 8,28 \\
\hline 1975 & 183.073 & 26.311 & 6,96 & 2,13 & 0,31 & 3,04 \\
\hline 1976 & 61.817 & 40.846 & 1,51 & 0,70 & 0,46 & 4,44 \\
\hline 1977 & 88.123 & 51.786 & 1,70 & 0,99 & 0,58 & 3,17 \\
\hline 1978 & 151.106 & 66.207 & 2,28 & 1,72 & 0,76 & 2,40 \\
\hline 1979 & 195.526 & 75.055 & 2,61 & 2,27 & 0,87 & 1,75 \\
\hline 1980 & 317.252 & 60.222 & 5,27 & 3,80 & 0,72 & 5,55 \\
\hline 1981 & 333.024 & 57.454 & 5,80 & 4,09 & 0,71 & $-0,59$ \\
\hline 1982 & 294.030 & 61.805 & 4,76 & 3,64 & 0,77 & 1,50 \\
\hline 1983 & 283.543 & 59.984 & 4,73 & 3,55 & 0,75 & 1,91 \\
\hline 1984 & 278.135 & 68.990 & 4,03 & 3,63 & 0,90 & 1,10 \\
\hline 1985 & 239.674 & 74.776 & 3,21 & 3,14 & 0,98 & 2,93 \\
\hline 1986 & $221.597 *$ & 56.882 & 3,90 & 2,79 & 0,72 & 3,52 \\
\hline 1987 & $218.369 *$ & 48.166 & 4,53 & 2,63 & 0,58 & 6,61 \\
\hline 1988 & $229.030 *$ & 56.763 & 4,03 & 2,63 & 0,65 & 5,92 \\
\hline 1989 & 230.759 & 46.322 & 4,98 & 2,51 & 0,50 & 5,85 \\
\hline 1990 & 245.335 & 48.591 & 5,05 & 2,56 & 0,51 & 4,43 \\
\hline 1991 & 274.079 & 68.032 & 4,03 & 2,81 & 0,70 & 3,03 \\
\hline 1992 & 274.544 & 83.237 & 3,30 & 2,90 & 0,88 & 1,43 \\
\hline 1993 & 323.452 & 118.744 & 2,72 & 3,56 & 1,31 & $-0,99$ \\
\hline 1994 & 238.842 & 74.158 & 3,22 & 2,64 & 0,82 & 2,74 \\
\hline 1995 & 215.747 & 58.513 & 3,69 & 2,31 & 0,63 & 3,40 \\
\hline 1996 & 217.646 & 40.926 & 5,32 & 2,25 & 0,42 & 2,44 \\
\hline 1997 & 204.079 & 32.127 & 6,35 & 2,01 & 0,32 & 4,03 \\
\hline 1998 & 209.074 & 35.716 & 5,85 & 1,96 & 0,33 & 4,35 \\
\hline 1999 & 224.330 & 25.651 & 8,75 & 1,96 & 0,22 & 4,22 \\
\hline 2000 & 242.698 & 29.717 & 8,17 & 1,98 & 0,24 & 4,21 \\
\hline 2001 & 285.854 & 37.778 & 7,57 & 2,24 & 0,30 & 2,84 \\
\hline 2002 & 268.186 & 39.975 & 6,71 & 2,04 & 0,30 & 2,04 \\
\hline 2003 & 171.024 & 42.960 & 3,98 & 1,26 & 0,32 & 2,43 \\
\hline
\end{tabular}

Fuentes: Columnas primera y segunda, Ministerio de Trabajo y Seguridad Social: Boletín de Estadísticas Laborales (varios números) y García de Blas (1982). Los datos de asalariados utilizados para las columnas cuarta y quinta proceden del Instituto Nacional de Estadística: Encuesta de Población Activa. Los datos de tasas de crecimiento del PIB a precios de mercado, en pesetas constantes de 1995, proceden de Prados de la Escosura (2003, pps. 643-644), salvo para 1997-2003, que se han tomado directamente del Instituto Nacional de Estadística: Contabilidad Nacional de España.

Método de cálculo de la cifra de despidos individuales totales: en 1974-75 se han sumado los casos iniciados en el sindicato vertical -porque necesariamente todos los casos de las Magistraturas han pasado previamente por el sindicato vertical-; 1976-78 muestra el total de casos de las Magistraturas; 1979 recoge el total de casos de las Magistraturas con los casos pactados en MAC; de 1980 en adelante se recoge el total de casos iniciados en MAC -porque se produce la misma situación que antes, pero ahora respecto de los Juzgados de lo Social.

Nota: * Sin datos del País Vasco. 
Esta relación entre despidos individuales y colectivos -disciplinarios y económicos, en definitiva- nos está indicando que el verdadero instrumento de ajuste de plantillas en España ha sido y es el despido individual, con lo que, detrás de la gran cantidad de despidos disciplinarios, tiene que haber forzosamente una inmensa mayoría de despidos económicos encubiertos. Adicionalmente, si los despidos disciplinarios realmente fueran tales no deberían tener una pauta contracíclica como la que tienen. Con los datos del Cuadro 1 se puede obtener la correlación de la ratio de los despidos individuales en términos del número de asalariados en relación con la tasa de crecimiento del PIB, que es negativa $(-0,38)$, igual que sucede con la misma correlación para los despidos colectivos (que alcanza -0,51). Aunque el coeficiente de correlación sólo denota asociación y no causalidad, vemos que los despidos individuales mantienen una relación clara con las oscilaciones de la actividad económica, aumentando en las fases recesivas del ciclo y disminuyendo en las expansiones. Este tipo de asociación entre las variables no debería ocurrir si realmente fueran despidos disciplinarios, pues en situación de crisis el coste de oportunidad para el trabajador de no cumplir sus tareas y ser despedido por ello es mucho más elevado en tiempos de crisis -al ser más difícil encontrar un nuevo empleo-, lo cual promueve un mayor cumplimiento de las obligaciones durante las crisis.

Por lo tanto, la práctica jurídica ha llevado a un uso desvirtuado de las causas para despedir, favoreciendo las disciplinarias. Dado que el despido individual disciplinario ha sido, cuantitativamente, el mecanismo de ajuste de plantillas más utilizado, el análisis de este tipo de despido es el que tiene que ocupar el lugar central del análisis sobre el despido en España.

Sin embargo, ¿es este razonamiento aplicable a todo el periodo franquista? $¿$ Cabe conjeturar que se produjo el mismo uso desvirtuado de las causas disciplinarias en contra de la causa económica?

La legislación franquista de la autarquía, en referencia a la Ley de Contratos de Trabajo de 1944, recoge la causa económica para despedir siguiendo a la Ley de Jurados Mixtos de 1931, pero sumando el requisito añadido durante el Bienio Conservador de la República de solicitar autorización a la Administración con carácter previo a la realización de los despidos económicos. La autoridad administrativa daba o no su autorización previo informe de la Inspección de Trabajo y de la Organización Sindical, interviniendo en ocasiones la jurisdicción laboral en la fijación de indemnizaciones. En este momento histórico no tendría sentido hablar de despidos colectivos en el sentido actual, sino más bien de que los despidos económicos eran como múltiples despidos individuales realizados simultáneamente, puesto que los trabajadores no tenían una voz colectiva frente a los mismos -a la manera de los actuales despidos económicos objetivos introducidos en 1994. Este procedimiento se mantiene hasta el Decreto 3090/1972 que mantiene el requisito de la autorización previa por parte del Ministerio de Trabajo, pero que ya trata los 
despidos económicos como despidos que afectan de manera simultánea a todo un conjunto de trabajadores ${ }^{2}$. Incorporada a distintas leyes, esta normativa franquista pervivió durante la Transición, si bien, al desaparecer los Jurados de Empresa en 1976, la tramitación del llamado «expediente de crisis» comenzó a requerir informes de los (ahora sí) representantes de los trabajadores en la empresa, con lo que se abrió la puerta a lo que ya se implantó en el Estatuto de los Trabajadores: la necesidad de una negociación entre trabajadores y empresa para llegar a un acuerdo sobre las condiciones del despido colectivo, legalmente denominado «expediente de regulación de empleo» ${ }^{3}$.

Por consiguiente, durante todo el franquismo hasta 1973 los despidos económicos -por muy colectivos que fueran- eran tratados como cuestiones individuales entre cada trabajador y su empleador, «cuidando» de la vigilancia de los trabajadores la Organización Sindical y la Administración Laboral a través de sus respectivos informes.

A diferencia de lo que ocurre a partir de 1974, no contamos con anterioridad con series de datos oficiales públicos de despedidos en despidos colectivos, sino sólo de los individuales ${ }^{4}$. Estos datos se presentan en el Cuadro 2. No obstante, Mingo (1994) afirma que el recurso a las causas disciplinarias era frecuente, debido a la facilidad de su uso gracias a una redacción de la norma muy amplia y de escasa concreción -algo típico de la legislación laboral franquista como destaca Babiano (1995, cap. 2). Incluso en el caso de que la empresa utilizara una causa disciplinaria totalmente insostenible, podía resolver sencillamente el despido mediante posterior acuerdo con el trabajador, proporcionando una indemnización en el acto de conciliación en el sindicato vertical ${ }^{5}$. Esta «facilidad» del recurso al despido disciplinario debe compararse con la necesidad de autorización previa en caso de alegar causas económicas. Así pues, cabe pensar que, salvo en situacio-

${ }^{2}$ Fina et al. (1989) señalan que, en el final del franquismo, aunque los representantes de los trabajadores -encuadrados en la Organización Sindical- eran consultados, en algunos casos los trabajadores los «puenteaban» haciendo directamente propuestas de viabilidad y de respuesta a la crisis que afectaba a la empresa.

${ }^{3}$ Para una revisión jurídica detallada de la evolución de los despidos por razones económicas desde la Segunda República hasta 1994, véanse los capítulos introductorio y primero de Del Valle (1996).

${ }^{4}$ En los números del Anuario Estadístico del INE de los años cincuenta y primeros sesenta aparecen datos sobre número de expedientes de crisis resueltos por la Administración Laboral que permiten reconstruir una serie de expedientes de crisis entre 1952 y 1960, pero sólo para un año (1960) se ofrecen estos datos en términos de número de despedidos. Estas series están a disposición de los interesados.

${ }^{5}$ La conciliación forzosa en el sindicato vertical se formalizó legalmente en 1958, pero ya se incluía dicha conciliación en la normativa desde 1950: vid. Mingo (1994). No obstante, se cuenta con datos sobre conciliaciones en el Sindicato Vertical desde 1943, como muestran los datos recogidos por García de Blas (1982) y reproducidos en el Cuadro 2. 
nes en que la empresa necesitara una reducción rápida de plantilla -algo propio de momentos de crisis económicas graves y generalizadas-, se utilizara más la causa disciplinaria que la económica. Una observación aislada de despedidos en despidos colectivos disponible para 1960 -véase nota 4- nos dice que en dicho año se despidieron mediante expedientes de crisis de reducción de plantilla y de cierre de empresa 31.190 trabajadores. Tomando el número correspondiente de despidos individuales en 1960 -según el Cuadro 2, 89.311 despidos-, tendríamos una ratio de individuales frente a colectivos de 2,86. Esta ratio es equiparable a las que en el Cuadro 1 se ofrecen para años de crisis económica como 1978, 1979 y 1993. Teniendo en cuenta que el Plan de Estabilización de 1959 estuvo relacionado en un primer momento con un proceso de reestructuración y que la tasa de crecimiento del PIB en 1959 fue de -0,5 por ciento y en 1960 de 1,7 -valores propios de periodos de crisis económicas y de reestructuración 6 -, podemos deducir que esta observación aislada es muy coherente con la interpretación que aquí se ha dado al uso relativo de despidos individuales y colectivos, mostrando una realidad semejante a la del periodo para el cual contamos con el mismo tipo de información estadística (1974-2003).

Por tanto, los despidos individuales y, dentro de estos, los disciplinarios, se han constituido en la principal vía de ajuste, tanto en el franquismo como en la democracia, lo cual justifica centrarse en su estudio, tal como se propuso al inicio de este apartado ${ }^{7}$. Obviamente, necesitamos profundizar en esta cuestión para ir más allá de la constatación del uso distorsionado de los tipos de despido y avanzar en por qué ha ocurrido esto tanto bajo la dictadura como durante la democracia.

${ }^{6}$ Estas tasas de crecimiento están calculadas con los datos sobre PIB a precios de mercado, en pesetas constantes de 1995, ofrecidos por Prados de la Escosura (2003, p. 644).

${ }_{7}^{7}$ Cabe preguntarse si no eran posibles los despidos económicos no colectivos. En principio, sí que ha sido posible, pero durante el franquismo -de hecho hasta 1977- esto equivalía a hacer un expediente de crisis para un solo trabajador, algo que no parecía demasiado atractivo teniendo en cuenta los costes fijos de la autorización previa. En 1977 un decreto permitió tal posibilidad - un despido económico de un trabajador sin recurrir a un expediente ni a la autorización previa-, pero su uso era difícil y ha sido más una anécdota que una posibilidad realmente utilizada; sobre el particular, vid. Briones (1995). También ha sido posible durante la vigencia del Estatuto de los Trabajadores hacer un expediente de regulación de empleo para un solo trabajador, pero de nuevo no es una opción atractiva por los costes fijos que conlleva. Sólo es con la reforma de 1994 -y la ampliación de la figura del despido económico de 1977que pueden comenzar a realizarse despidos económicos individuales, como se explicará con detalle en el apartado 4. Por tanto, sólo a partir de dicho año la serie de despidos individuales del Cuadro 1 puede ser que contenga una cierta cantidad de despidos económicos, sin que se pueda tener una idea de cuántos realmente son, ni con los datos administrativos de mediación, ni con los de los Juzgados de lo Social, ni con los datos del Sistema Integrado de Prestaciones del INEM. 
CUADRO 2

CASOS DE DESPIDO EN LA ORGANIZACIÓN SINDICAL Y EN LAS MAGISTRATURAS DE TRABAJO

\begin{tabular}{|c|c|c|c|c|c|}
\hline \multirow{2}{*}{ Año } & \multicolumn{4}{|c|}{$\begin{array}{l}\text { Actos de conciliación de despidos } \\
\text { en la Organización Sindical }\end{array}$} & \multirow{2}{*}{$\begin{array}{c}\text { Magistra- } \\
\text { turas de } \\
\text { Trabajo }\end{array}$} \\
\hline & $\begin{array}{c}\text { Total } \\
\text { de } \\
\text { actos } \\
\end{array}$ & $\begin{array}{c}\text { Actos } \\
\text { con } \\
\text { avenencia }\end{array}$ & $\begin{array}{c}\text { Actos } \\
\text { sin } \\
\text { avenencia }\end{array}$ & $\begin{array}{c}\text { Porcentaje } \\
\text { de } \\
\text { avenencia }\end{array}$ & \\
\hline 1943 & 10.302 & 7.136 & 3.166 & 69,3 & 8.805 \\
\hline 1944 & 31.140 & 23.281 & 7.859 & 74,8 & 11.977 \\
\hline 1945 & 46.573 & 38.982 & 7.591 & 83,7 & 15.423 \\
\hline 1946 & 49.488 & 39.982 & 9.506 & 80,8 & 21.852 \\
\hline 1947 & 175.225 & 151.958 & 23.267 & 86,7 & 20.285 \\
\hline 1948 & 136.274 & 108.443 & 27.831 & 79,6 & 22.048 \\
\hline 1949 & 119.724 & 99.502 & 20.222 & 83,1 & 23.597 \\
\hline 1950 & 108.689 & 78.761 & 29.928 & 72,5 & 21.924 \\
\hline 1951 & 99.188 & 68.753 & 30.435 & 69,3 & 19.754 \\
\hline 1952 & 111.710 & 79.421 & 32.289 & 71,1 & 20.431 \\
\hline 1953 & 103.379 & 67.171 & 36.208 & 65,0 & 22.747 \\
\hline 1954 & 108.731 & 74.303 & 34.428 & 68,3 & 21.933 \\
\hline 1955 & 96.676 & 67.804 & 28.872 & 70,1 & 19.985 \\
\hline 1956 & 86.200 & 60.144 & 26.056 & 69,8 & 16.725 \\
\hline 1957 & 85.464 & 59.718 & 25.746 & 69,9 & 19.620 \\
\hline 1958 & 86.288 & 61.750 & 24.538 & 71,6 & 16.638 \\
\hline 1959 & 92.215 & 63.369 & 28.846 & 68,7 & 16.580 \\
\hline 1960 & 89.311 & 61.836 & 27.475 & 69,2 & 15.829 \\
\hline 1961 & 83.940 & 57.747 & 26.193 & 68,8 & 13.680 \\
\hline 1962 & 100.221 & 70.509 & 29.712 & 70,4 & 12.367 \\
\hline 1963 & 108.559 & 76.586 & 31.973 & 70,5 & 16.186 \\
\hline 1964 & 123.737 & 81.078 & 42.659 & 65,5 & 16.383 \\
\hline 1965 & 116.499 & 79.062 & 37.437 & 67,9 & 16.647 \\
\hline 1966 & 124.259 & 84.379 & 39.880 & 67,9 & 17.150 \\
\hline 1967 & 146.909 & 96.971 & 49.938 & 66,0 & 23.957 \\
\hline 1968 & 129.949 & 70.386 & 59.563 & 54,2 & 24.850 \\
\hline 1969 & 115.594 & 62.256 & 53.338 & 53,9 & 23.530 \\
\hline 1970 & 129.530 & 68.692 & 60.838 & 53,0 & 25.902 \\
\hline 1971 & 162.246 & 86.750 & 75.496 & 53,5 & 35.073 \\
\hline 1972 & 177.562 & 109.978 & 57.584 & 61,9 & 32.676 \\
\hline 1973 & 165.541 & 93.121 & 72.420 & 56,3 & 31.104 \\
\hline 1974 & 157.691 & 80.528 & 77.163 & 51,1 & 37.466 \\
\hline 1975 & 183.073 & 96.222 & 86.851 & 52,6 & 47.654 \\
\hline
\end{tabular}

Fuentes: Para los datos de la Organización Sindical, García de Blas (1982); para los datos sobre las Magistraturas, Instituto Nacional de Estadística: Anuario Estadístico de España (varios números). 


\section{LA EVOLUCIÓN DE LA LEGISLACIÓN SOBRE DESPIDO EN ESPAÑA Y LOS CAMBIOS EN EL SISTEMA DE RELACIONES LABORALES}

El régimen jurídico del despido es uno de los componentes fundamentales de cualquier sistema de relaciones laborales. Por lo tanto, al analizar la evolución de la legislación sobre despidos es inevitable describir otras normas que regulan otros aspectos de la relación laboral, ya que se complementan mutuamente. A continuación se analiza dicha evolución, desde los antecedentes más importantes de la legislación sobre despidos, haciendo especial referencia a la determinación de indemnizaciones y a la exigencia de una causa para realizar el despido. No obstante, se intenta ir más allá de la mera descripción, destacando los incentivos que la legislación otorgaba a la empresa para usar unos u otros procedimientos para despedir. Debe tenerse en cuenta que, aunque en este apartado se otorga especial importancia a la evolución jurídica, no se considera que la legislación tenga vida propia, sino que está relacionada con su momento histórico, económico y social, debiendo entenderse dentro de las transformaciones históricas del mercado de trabajo español.

\subsection{Antecedentes}

Aunque pueden citarse precedentes anteriores a la Segunda República -véase Rodríguez Fernández (1989)-, el antecedente más importante en relación con los despidos es la Ley de 27 de noviembre de 1931 de Jurados Mixtos. Esta ley completó el régimen jurídico del despido de la Ley de Contratos de 1931, y se enmarca dentro del intenso momento legislativo laboral impulsado por el socialista Largo Caballero, analizado por Mingo (1994). Como ya se dijo en el apartado 3, introdujo la exigencia de causa justa para despedir, dividiendo las causas en imputables al trabajador -típicamente disciplinarias- y las no imputables al mismo -por ejemplo, las razones económicas. Cabe destacar también que los Jurados Mixtos estaban facultados para apreciar la legitimidad del despido ${ }^{8}$. La readmisión del despedido en caso de falta de causa legítima del despido podía ser sustituida por una compensación económica (una indemnización).

Durante el Bienio Conservador (1993/1935) se introduce la intervención administrativa en los despidos por razones económicas, mediante el Decreto de 29 de noviembre de 1935 sobre despido parcial de obreros por falta de trabajo. Esta

\footnotetext{
${ }^{8}$ En los Jurados Mixtos participaban tanto funcionarios judiciales como representantes de las asociaciones existentes. Su estructura era la siguiente: un presidente, un secretario e igual número de vocales para empresarios y trabajadores. Eran, pues, semejantes a los Tribunales Industriales que todavía existen en algunos países de la Unión Europea, como es el caso del Reino Unido.
} 
medida se ha interpretado por Del Valle (1996) como un intento de luchar contra el desempleo controlando la salida de trabajadores de las empresas: de hecho, el mencionado decreto era un desarrollo de la Ley de Paro Obrero de junio de 1935. Del Valle (1996) señala que esta medida trataba de frenar el proceso de destrucción de puestos de trabajo amparado en la causa económica, aludiendo los empresarios de manera genérica a la crisis económica mundial y utilizando el incremento del paro a nivel local como un instrumento político contra la República9 También Del Valle (1996, p. 86) ve en esta medida una muestra de paternalismo estatal por parte de los gobernantes de la CEDA, anticipando prácticas paternalistas del sistema de relaciones laborales franquista. Pero, además, se constituye en el inicio de la intervención administrativa en los despidos por razones económicas, que acabará por hacer más atractivo el despido individual de tipo disciplinario para, en realidad, reducir la plantilla por razones económicas, como se explicó al final del apartado 3.

\subsection{La normativa de la dictadura: el periodo autárquico y el sistema clásico de despido}

Tal vez más importante que el cambio en las «reglas de juego» que trajo la dictadura, y que la letra de la normativa, era su aplicación de modo represivo y excluyente -vid. Cazorla (2000)-, de manera que no sólo se prohibían las manifestaciones colectivas del conflicto laboral como las huelgas o la mera sindicación libre, sino que el empresario llegaba a constituirse en una especie de representante del Estado -y de sus fines políticos- en el seno de la empresa: al respecto, véase Babiano (1995 y 1998).

Las primeras normas franquistas relacionadas con el mercado de trabajo nacen ya durante la Guerra Civil ${ }^{10}$. El nuevo marco institucional se va asentando en los primeros años cuarenta con una profusión de normas de distinto nivel, que en muchas ocasiones no derogaban por completo la normativa republicana anterior, aumentando las dificultades de interpretación y aplicación. En relación con los

\footnotetext{
${ }^{9}$ Siguiendo a Preston (1987, p. 137), tras las elecciones de 1933 se produjo un intenso momento de extensión del desempleo, alcanzando el 12 por cien a nivel nacional, pero con tasas un 50 por cien más altas en las provincias más afectadas (Jaén, Badajoz y Córdoba). Preston (1987, p. 137) también alude a los despidos realizados por mera represalia contra los «revoltosos» de 1932. Sobre el incremento del desempleo a pesar de la mejora de los indicadores de producción en dicho momento, véase Tuñón (1976, vol. II, p. 99).

${ }^{10}$ El Fuero del Trabajo se aprueba en 1938 e introduce dos cambios sustanciales en el sistema de relaciones laborales: introduce una nueva Magistratura para los asuntos laborales y crea el sindicato vertical. Se suprimieron los Jurados Mixtos (Decreto de 13 de mayo de 1938) y las Magistraturas de Trabajo, con una estructura típicamente judicial, pasan a asumir sus funciones.
} 
despidos, es muy llamativa la continuidad de gran parte de la normativa republicana, adaptada al corte totalitario del nuevo sistema político, tanto que los nuevos desarrollos legislativos sobre despidos parecen avanzar en la lógica inicial de aquella normativa, aunque siempre con el aspecto totalitario y controlador del franquismo. En este sentido, la Guerra Civil no generó una ruptura en la legislación sobre el despido, sino una adaptación al nuevo tipo de gobierno. Veamos con algo de detalle cómo se plasmó esa continuidad con adaptación en las leyes relacionadas con los despidos de 1941 y 1944.

En 1941, por un lado, se legislan las causas de cese del contrato de trabajo y de despido disciplinario (Ley 6 de noviembre de 1941, que modifica el artículo 89 de la Ley de Jurados Mixtos de 1931). Por otro lado, se establece el régimen de indemnizaciones en relación con la opción del patrono o del obrero (Ley 6 de noviembre de 1941, que modifica la Ley de Jurados Mixtos). Esta ley afirmaba que era un contrasentido jurídico -y algo en contra del derecho al trabajo establecido en el Fuero del Trabajo- que en caso de despido injustificado el empresario tuviera el derecho de opción entre readmitir o compensar, cuando fue él quien hizo el despido sin causa justa. Sin embargo, también se establecen salvedades para las pequeñas empresas, para la que se implanta un régimen de despido propio. Hay consecuencias nuevas si el despido es calificado como injusto: si la empresa tenía más de 50 operarios fijos, la opción era del trabajador, mientras que, si la empresa tenía menos de esa cifra, la opción era de la empresa. Teniendo en cuenta la estructura industrial de España -con predominio de la pequeña empresa-, el caso más habitual sería el segundo.

En 1944 se cierra la provisionalidad de la regulación de las relaciones individuales de trabajo con las siguientes normas: la Ley de Contratos de Trabajo (LCT) de 26 de enero de 1944, que se basaba, en líneas generales, en la Ley de Jurados Mixtos de la Segunda República -lo cual muestra la continuidad a la que se aludía antes-, y los artículos 222, 223 y 224 del Código Penal sobre la represión de los fenómenos huelguísticos y de protesta colectiva -lo cual ilustra la adaptación al sistema dictatorial a la que nos hemos referido antes.

La LCT de 1944 incluye una enumeración de las causas de despido (9 categorías). El despido disciplinario aparece bajo el nombre de despido justificado. Mingo (1994) ha argumentado que las causas de despido disciplinario permitían su uso como instrumento represivo. Así, la enumeración de motivos del despido disciplinario no generaba rigidez, sino que permitía una amplia maniobrabilidad a la empresa, ya que la legislación no detallaba las faltas ni el grado de gravedad: estos aspectos se dejaban a criterio del reglamento de régimen interior y de la discrecionalidad del empresario.

La LCT de 1944 mantuvo las consecuencias del derecho de opción en función del tamaño de la empresa descritas más arriba. En cuanto a la compensación económica, ésta era fijada por el Magistrado a su prudente arbitrio -pudiendo tener 
en cuenta la situación personal y familiar del trabajador-, sin que el importe pudiera exceder de un año de jornal.

Dos cuestiones importantes relacionadas con el despido planteadas por la LCT de 1944 fueron la forma del despido y el incumplimiento de la readmisión.

En cuanto al primer problema, la LCT, al igual que sus predecesoras, no mencionaba la forma del despido, y, de acuerdo con la interpretación de Almansa (1968), fueron las Reglamentaciones de Trabajo las que llenaron este vacío exigiendo un expediente previo, en el que debían oírse las alegaciones del interesado.

En relación con la segunda cuestión, si el empresario no readmitía al trabajador, la situación de éste era muy confusa, ya que no contaba con medios para hacer valer su opción cuando el patrono se oponía a ello.

En definitiva, las incertidumbres en la aplicación de las instituciones relacionadas con el despido eran muy elevadas durante el periodo autárquico, lo cual otorgaba amplia capacidad de interpretación a los jueces y creaba grandes incertidumbres a los trabajadores a la hora de presentar sus quejas o reclamaciones. Esto no era algo propio de la normativa del despido, sino, como señala Babiano (1995), de todo el ordenamiento laboral franquista.

Durante la década de los cincuenta, en un momento en que aflora la conflictividad social en forma de huelgas y reclamaciones colectivas -estudiado por Molinero e Ysàs (1998, cap. 1)-, el sistema de relaciones laborales descrito antes se muestra incapaz de ayudar a hacer frente a la precaria situación económica del final del periodo autárquico ${ }^{11} \mathrm{y}$, a partir de 1956, se abre un periodo de cambios legales que desemboca en una nueva articulación del sistema de relaciones laborales, sobre todo en lo que se refiere al despido y las indemnizaciones.

El Decreto de 26 de octubre de 1956 genera una gran cantidad de novedades en relación con el despido, que las normativas posteriores fijarán y completarán ${ }^{12}$, pero sin cambiar sus principios. Este decreto unificó los criterios de forma, eliminó el sistema de despido propuesta, y la necesidad de expediente. En su lugar, aparecen ya los aspectos básicos del sistema clásico español que se suele asociar con todo el periodo franquista: carta de despido - con fecha y motivos del despido-; distinción entre despido improcedente y nulo; e incidente de no readmisión, que regula la sustitución de la obligación de readmitir por una cierta compensación económica más elevada que la indemnización estipulada inicialmente. Por tanto, se produce una simplificación del despido y una aclaración de las incertidumbres previas.

Aunque todos los componentes del esquema clásico son relevantes, cabría destacar la aparición del incidente de no readmisión -cuya denominación legal

\footnotetext{
${ }^{11}$ Para una revisión de las vicisitudes del mercado de trabajo español durante la autarquía véase, por ejemplo, Soto (2003).

${ }^{12}$ Estas normas son el Texto Refundido de Procedimiento Laboral (TRPL) de 4 de julio de 1958, el TRPL de 17 de enero de 1963, el Texto Articulado de Procedimiento Laboral de 21 de abril de 1966 y el TRPL de 17 de agosto de 1973.
} 
completa era la de incidente de indemnización de daños y perjuicios por la no readmisión-, ya que tiene como efecto que la decisión de despido de la empresa es definitiva aunque el despido sea nulo, si bien pagando un precio mayor por ese despido. El funcionamiento de todo el procedimiento, incluido el del incidente de no readmisión, se explica a continuación.

La formulación del TRPL de 4 de julio de 1958 permitía, mediante la interacción de sus artículos 103 y 212, la existencia del despido sin causa costoso, ya que, según el artículo 103, en los despidos disciplinarios injustificados -improcedentes, en la terminología jurídica actual- el magistrado debía condenar al empresario a la readmisión o al pago de una indemnización de hasta un año de salario, correspondiendo la opción a la empresa cuando ésta tuviera una plantilla de menos de 50 trabajadores, y al trabajador en caso contrario. Pero aquí entraba en juego el artículo 212, puesto que, si la empresa no cumplía la obligación de readmitir, las consecuencias para ésta eran el pago de una indemnización de hasta cuatro años de salario y la extinción definitiva de la relación laboral. Esta situación, prevista por el artículo 212, era precisamente el incidente de no readmisión ${ }^{13}$.

Para la interpretación económica de la modificación jurídica que supone el incidente de no readmisión, hay que situarla en su contexto histórico. Se produce al comenzar el fin de la autarquía, y ante el reto de la apertura de los mercados al exterior. La estructura productiva anquilosada y radicalmente no competitiva del primer franquismo exigía cambios y adaptaciones ante la grave crisis económica de 1955-56, que vino acompañada de agitaciones sociales ${ }^{14}$. En este contexto, el incidente de no readmisión se configura como solución de compromiso o, más bien, como «contraprestación» a los empresarios de la posibilidad de mejoras voluntarias en los salarios. En este sentido hay que decir que, previamente al incidente de no readmisión, el Decreto de 8 de junio de 1956 había reconocido a la empresa el derecho a fijar, sin autorización del Ministerio de Trabajo, condiciones salariales superiores a las establecidas en las Reglamentaciones, que adquirían así el carácter de mínimos. Por tanto, de acuerdo con la interpretación de Rodríguez Fernández (1989), la mayor facilidad para el despido del incidente de no readmisión se introduce como contrapeso de las mejoras respecto de los mínimos salariales. Pero esta justificación de carácter histórico -en el sentido de que depende de circunstancias únicas que se dieron en un cierto momento- dio entrada de forma clara en el ordenamiento jurídico español al despido libre costoso, ya que bastaba con cumplir los requisitos de forma y con pagar una cierta cantidad de dinero

\footnotetext{
${ }^{13}$ Sic. En Rodríguez Fernández (1989). Los detalles estrictamente jurídicos del incidente de no readmisión son revisados en Montoya (1978). Un análisis con mayor extensión y profundidad se puede encontrar en Alonso (1970) y en Rodríguez Fernández (1989).

${ }^{14}$ Para una descripción de la conflictividad social durante el periodo autárquico véase, por ejemplo, Molinero e Ysàs (1998, cap. 1).
} 
para que el despido tuviera lugar con independencia de la «verdad» de la causa alegada. Ahora bien, las cantidades pagadas se desvinculaban de las que podría haber previsto la normativa para los despidos económicos, porque aparecían incentivos para no usar la normativa creada para los despidos económicos -que necesitaban de autorización administrativa previa y de informes de la Inspección de Trabajo y de la Organización Sindical, como se explicó en el apartado 3-, sino para usar el camino más sencillo y rápido del despido disciplinario, pero a un coste más elevado. Es aquí dónde se aprecia nuestro alejamiento de la interpretación habitual, cuya referencia clásica es Serrano y Malo de Molina (1979). Los mecanismos de la carta de despido, exigencia de causa, etc., no se establecen para generar una seguridad en el empleo que sirva de contrapeso a la flexibilidad salarial, sino que nacen y se fijan junto con el mecanismo del incidente de no readmisión, clarificando legalmente el cauce ya existente para el despido libre costoso, ya que bastaba con cumplir los requisitos de forma y con pagar una cierta cantidad de dinero para que el despido tuviera lugar. La normativa proporcionaba, así, incentivos para un uso desvirtuado de la misma, de tal manera que, si los casos llegaban hasta el juez, éste no podría por menos que fallar a favor del trabajador debido a los incentivos creados para usar inadecuadamente la norma, y no meramente por el paternalismo habitualmente atribuido a la justicia laboral bajo la dictadura franquista ${ }^{15}$. Como señala Valdés (1985), no es evidente que el sistema franquista proporcionara estabilidad en el empleo a cambio de la falta de derechos colectivos, como se suele afirmar en muchas ocasiones -tanto, que podríamos decir que dicha afirmación forma parte de la sabiduría convencional sobre la historia del mercado de trabajo español. La estabilidad, más bien, la proporcionaba la situación económica, ya que, como fue evidente más tarde, la legislación franquista no fue capaz de proporcionar estabilidad ante una situación de crisis generalizada.

Esta mayor facilidad para despedir -en realidad, otorgada a las empresas de más de 50 trabajadores, que eran aquellas en las que el derecho de opción lo tenía el trabajador-, les debía permitir renovar su personal y adaptar su actividad productiva, diseñada para una economía autárquica, permitiendo mejorar su competitividad de cara al comercio exterior. Algunos autores, como Rodríguez Fernández (1989), insisten en que el aumento de la indemnización podría estar encaminado a reducir la contestación de los trabajadores. Sin embargo, hay que señalar que el aumento de la indemnización no se aplica en el incidente de no readmisión de las empresas de menos de 50 trabajadores. Teniendo en cuenta la gran cantidad de empresas pequeñas en España, esto es muy importante, y suponía,

\footnotetext{
${ }^{15}$ Algunos autores consideran que este paternalismo también ha sido relevante tras la llegada de la democracia: así Jimeno y Toharia (1993). Un análisis teórico y empírico del paternalismo de los jueces laborales, pero en el caso italiano, lo constituye Ichino et al. (2003).
} 
en realidad, la instauración de un sistema de compensación en el que el tamaño de la indemnización dependía del tamaño de la empresa.

Esto nos lleva a la cuestión de cuán importante era la aplicación de esta vía de reducción de plantilla. En el momento en que aparece esta vía de despido libre costoso, para el conjunto de la economía española era forzosamente poco importante. La preponderancia del sector agrario implicaba que la normativa anterior no se aplicaba a la mayoría de la fuerza de trabajo española, ya que en dicho sector habitualmente los contratos laborales no se formalizaban, y muchos de ellos no eran permanentes, aunque se repitieran a lo largo del tiempo. En definitiva, la extensión de las relaciones laborales basadas en el contrato indefinido limitaba severamente la importancia de esta normativa. Siguiendo a Fina et al. (1989), la proporción de temporales en empresas de más de diez trabajadores en el sector de la construcción y en el de alimentación, bebidas y tabaco era del 40 y del 32 por cien a principios de los sesenta, respectivamente, mientras que en 1976 dicha proporción se había reducido en ambos sectores a cifras en torno al 15 por cien. No obstante, el impacto sobre la competitividad de este cauce para el despido libre costoso fue potencialmente beneficioso para las grandes empresas, que tuvieron en su mano una vía para despedir trabajadores rápidamente y sin la necesidad de recurrir a un expediente previo ni de solicitar autorización administrativa previa. De hecho, Rodríguez Fernández (1989) señala que fueron las grandes empresas las que presionaron para que se creara algún tipo de mecanismo legal que permitiera reducir las plantillas más fácilmente que con la legislación previa al incidente de no readmisión.

Finalmente, en relación con los costes burocráticos del despido, el Decreto de 1956 introdujo una novedad relacionada con el régimen jurídico de la ejecución de la condena de readmisión, y que puede interpretarse como un precedente histórico de los salarios de tramitación. Cuando el Magistrado juzgaba como arbitrario el despido, condenaba al empresario al pago de una indemnización complementaria calculada como el salario de las jornadas laborales equivalentes a la duración del proceso. No obstante, el TRPL de 1958 no hacía ninguna alusión a estas indemnizaciones complementarias, al igual que el resto de las normas procesales. Esto supuso la supresión de este embrión de los salarios de tramitación, pero hay que resaltar que este precedente histórico de los salarios de tramitación tuvo un claro carácter indemnizatorio supletorio y no significaba que la relación laboral continuaba hasta que el juez decidía calificar como improcedente el despido realizado por la empresa ${ }^{16}$.

En resumen, el TRPL de 1958 confirma el procedimiento que ya existía para el despido, pero aumentando el poder de decisión del empresario mediante la conju-

\footnotetext{
${ }^{16}$ Como veremos, esto se sigue apreciando incluso en los debates en torno a la reforma de las prestaciones por desempleo de 2002.
} 
gación de sus artículos 103 y 212. El régimen indemnizatorio, que pervivió hasta la Transición, era el siguiente:

- Si es declarado improcedente por el juez (artículo 103): readmisión o indemnización de hasta 1 año de salario.

- La opción es del patrono si la empresa tiene menos de 50 operarios fijos.

- La opción es del trabajador en caso contrario. La empresa solía incumplir la sentencia arguyendo el principio de autoridad. El artículo 212 establecía las consecuencias del incidente de no readmisión: ampliación de la indemnización hasta cuatro años de salario.

Así se aprecia claramente que el despido disciplinario era siempre posible, con causa o sin ella; para el empresario, todo se reducía a un problema de mayores costes y de cumplir los requisitos formales.

En los años sesenta y setenta cambió el escenario económico y social, y también el laboral. El crecimiento económico estuvo acompañado de grandes movimientos migratorios desde las zonas rurales a las urbanas y, junto con un ensanchamiento de la población activa, se transformó totalmente la estructura social española. Este proceso está abundantemente documentado, como puede verse, entre otros, en Molinero e Ysàs (1998), Babiano (1995) o Serrano y Malo de Molina (1979). La transformación sectorial es decisiva, perdiendo importancia paulatinamente el sector primario en beneficio del sector industrial. Esta nueva economía española se encontró con una regulación laboral cuyos principios rectores nacen con el primer franquismo, con una vocación de control e incluso de represión, como vimos al principio del apartado. Respecto de nuestro foco de atención, el despido, esto significa que el cambio sectorial y el crecimiento económico condujeron a una cada vez mayor aplicabilidad de los mecanismos de despido nacidos como una respuesta a una situación histórica determinada -las necesidades de reducción de plantilla de las grandes empresas durante el periodo final de la autarquía. Como señala Babiano (1998), la normativa franquista reflejaba una concepción de un mercado de trabajo basado en relaciones contractuales de largo plazo, junto con mercados internos de trabajo. En definitiva, algo que encaja con una economía con predominio del sector industrial. Por tanto, es en los años sesenta y setenta cuando la normativa franquista -el sistema clásico de despido en nuestro caso- se vuelve relevante para el conjunto de la economía.

\subsection{Transición y democracia}

Entre 1976 y 1980, la legislación laboral española es vacilante y, en ocasiones, trata de dar una respuesta a la nueva situación tratando de imponer soluciones drásticas, mientras que, en otras, trata de encaminarse hacia un sistema de rela- 
ciones laborales como el existente en el resto de países de Europa Occidental. En definitiva, los cambios en la normativa laboral reflejan los vaivenes del periodo de transformación de la dictadura en una democracia «sin rupturas», por usar el lenguaje de la época.

La primera ley de este periodo que cambia la regulación del despido es la Ley de Relaciones Laborales de 1976, complementada por el Real Decreto 1925/1976 de 16 de julio. Su principal novedad fue la imposición de la readmisión en caso de improcedencia -a través de su polémico artículo 35-, sin posibilidad de sustituirla por una indemnización ${ }^{17}$. De esta manera, esta ley sí que se proponía dar estabilidad en el empleo como contrapartida a la ausencia de derechos colectivos de los trabajadores -básicamente libertad sindical y derecho de huelga-, como señala Valdés (1985).

La Ley de Relaciones Laborales de 1976 buscaba la implantación de la estabilidad en el empleo por vía legal a fin de contrarrestar los primeros efectos de la crisis económica de los años setenta. El sistema establecido por esta ley eliminaba de raíz el despido sin causa costoso que había sido posible gracias al incidente de no readmisión, pero sin cambiar la regulación de los despidos económicos. No obstante, esta regulación apenas subsistió un año por el fuerte rechazo empresarial que suscitó, e incluso el polémico artículo 35, que imponía la readmisión, duró menos todavía ${ }^{18}$. Cabe conjeturar que una alteración en la normativa de los despidos económicos podría haber creado la vía de ajuste que solicitaban los empresarios, pero el Gobierno estaba más preocupado por generar apoyo al «franquismo sin Franco» a través de la estabilidad laboral que por reconducir el uso desvirtuado de los tipos de despido.

El Real Decreto Ley de Relaciones de Trabajo de 1977 introdujo nuevos cambios, destacando un nuevo tratamiento de las pequeñas empresas consistente en la reducción de la indemnización, si lo estimaba conveniente el juez, en las empre-

${ }^{17}$ Otras cuestiones que introdujo esta ley en relación con el despido fue el retorno al sistema de expediente, en sustitución del sistema de carta de despido, y la reaparición de la indemnización complementaria, que se acercaba a los actuales salarios de tramitación, con lo que se aprecia el carácter indemnizatorio de dichos salarios de tramitación.

${ }^{18}$ El Real Decreto Ley 18/1976 de 8 de octubre suspende el artículo 35 e introduce los siguientes cambios en los despidos: se equiparan los efectos del nulo y del improcedente, pero ahora en relación con la posibilidad de compensación por no readmisión; y el juez debía fijar la indemnización tomando como referencia la antigüedad en la empresa, las condiciones del contrato, las posibilidades de nueva colocación y las circunstancias personales y familiares del trabajador. La Orden Ministerial de 15 de octubre de 1976 clarificó aún más la situación en relación con los siguientes puntos: establecimiento de límites claros de la indemnización (artículo 2, disposición $2^{\mathrm{a}}$ ), que se situarían entre dos meses de salario por año de servicio y cinco anualidades -caso de tener al menos 30 años de servicio-, eliminación del expediente y reintroducción de la comunicación escrita al despedido, y mantenimiento de la indemnización complementaria, hasta la fecha en que el Magistrado da por finalizada la relación laboral. Para los detalles de todo el proceso, véase Valdés (1985). 
sas de menos de 25 trabajadores, y la creación de un nuevo tipo de despido llamado despido por causas objetivas, que incluía la posibilidad de despidos individuales por razones económicas. Sin embargo, como señala Briones (1995), esta figura apenas fue utilizada en la práctica, hasta la reforma del Estatuto de los Trabajadores de 1994, que vino a ampliar su aplicabilidad.

Pero el cambio más importante del periodo, ya tras la promulgación de la Constitución de 1978, lo constituye el Estatuto de los Trabajadores (ET) de 1980, que trataba de configurar unas reglas básicas de funcionamiento del mercado de trabajo coherentes con el nuevo sistema político democrático definido en la Constitución de 1978. En él se fijó una fórmula de cálculo de las indemnizaciones por despido disciplinario improcedente que permanece hasta hoy en día: 45 días de salario por año trabajado en caso de improcedencia, con un máximo de 42 mensualidades, es decir, tres años y medio de salario ${ }^{19}$. Con el ET, pues, se produce una reducción del máximo posible que podría llegar a pagar la empresa respecto de las leyes inmediatamente anteriores, y se elimina la discrecionalidad judicial a la hora de determinar las indemnizaciones. En general, lo que se aprecia en relación con el despido tanto en el ET de 1980 como en el decreto de 1977 es un intento de otorgar a las empresas una facilidad para realizar las reducciones de plantilla y las reestructuraciones relacionadas con la profundidad de la crisis económica que comienza a finales de los setenta. Malo de Molina (1983) valora esta situación como un intento (insuficiente) de compensar las subidas salariales relacionadas con la legalización de los sindicatos y la puesta en marcha de un verdadero sistema de negociación colectiva sin las trabas controladoras del sistema franquista.

La anterior valoración de Malo de Molina (1983) puede explicar el cambio, efectuado en 1984, en los costes de despido de los nuevos entrantes en el mercado de trabajo gracias a la reforma del ET, que permitía usar contratos temporales incluso para necesidades permanentes de la empresa, utilizando el llamado contrato temporal de fomento del empleo. Este cambio legislativo suscitó el apoyo de los empresarios, pero los sindicatos mayoritarios se dividieron en un primer momento: CCOO no lo apoyó, mientras que sí lo hizo UGT, alegando que mejoraría la entrada en el mercado de trabajo de los jóvenes -es decir, asumiendo los argumentos del gobierno del PSOE-, aunque, sobre todo tras la ruptura con el PSOE unos años más tarde, cambió su postura acerca de la extensión de la contratación temporal.

La generalización de los contratos temporales también supuso una alteración en la concepción de otro de los componentes del coste del despido que se con-

\footnotetext{
${ }^{19} \mathrm{Si}$ el despido disciplinario es procedente, no hay derecho a indemnización alguna, pero sí que hay derecho a percibir la prestación de desempleo, cumpliendo un breve periodo de mora.
} 
solidan con el ET: los salarios de tramitación. Con el ET éstos toman su forma actual. Si el proceso de despido se prolonga más de dos meses, el empresario tiene derecho a que la Administración le devuelva los salarios que excedan dicho límite. Así, los salarios de tramitación no parecen tener el carácter indemnizatorio en el que ya hemos insistido con anterioridad, sino que estarían relacionados con la interpretación de quién tiene derecho a romper la relación laboral: en caso de procedencia, el derecho es de la empresa, pero en caso de improcedencia, es del juez y, por tanto, la relación laboral pervive -y con ella el derecho a percibir el salario- hasta que el juez la rompe con la declaración de improcedencia. Ahora bien, esta concepción resulta trastocada por la práctica jurídica cuando se generalizan los contratos temporales. En caso de algún tipo de problema con la extinción del contrato temporal, el juez utiliza el régimen indemnizatorio del despido improcedente, ya que no se previó en ningún momento un régimen indemnizatorio propio y diferente para la extinción ilegal de un contrato temporal. Dada la baja antigüedad que, por definición, tiene un contratado temporal, una parte importante del dinero que percibe el temporal «despedido» corresponde a los salarios de tramitación. Por consiguiente, han adquirido finalmente la función indemnizatoria que tenían los «embriones» históricos previos de los salarios de tramitación ${ }^{20}, \mathrm{y}$ que ha estado en el núcleo de las reivindicaciones sindicales ante la reforma de las prestaciones por desempleo de 2002. Esto significa que los salarios de tramitación suponen un incremento del coste del despido sin ninguna justificación por razones de eficiencia ni de distribución -pues tienen que ver con la duración del proceso de despido y no con las pérdidas de ingresos del despedido, ni sus necesidades-, que perviven por la falta de un régimen indemnizatorio propio para los contratos temporales finalizados ilegalmente.

En 1994 vuelven a introducirse cambios en la normativa de los despidos en el ET (leyes 10/1994 y 11/1994). En la reforma del ET de 1994 se creó un nuevo tipo de despido económico de concreción individual y colectiva: el despido objetivo por razones económicas ${ }^{21}$. Este nuevo tipo de despido en realidad era una ampliación del despido económico individual introducido en 1977, y apenas utilizado

\footnotetext{
${ }^{20}$ Esto se puede comprobar con un ejemplo numérico sencillo. Sea un temporal con dos años de antigüedad y un salario de 30 euros por día. Si se produce una irregularidad en la finalización de su contrato, lo denuncia ante un juez y éste ratifica tal ilegalidad en el fin de contrato, se impone una indemnización de 45 días de salario por año trabajado, es decir, $45 \times 30 \times 2=2.700$ euros. Si el proceso ha durado tres meses (90 días), recibiría, además, por este concepto, 30x90=2.700 euros. Por tanto, los salarios de tramitación supondrían la mitad del total percibido por el trabajador (5.400 euros).

${ }^{21}$ Además, en esta reforma de 1994 se mantienen las causas de extinción, pero se produce una «descausalización» del despido. La ley califica de igual modo al despido sin forma que al carente de causa, y las anteriores causas de nulidad por defectos de forma lo son ahora de improcedencia. El resultado es una flexibilización de facto del despido, reservando la nulidad única y exclusivamente para despidos relacionados con discriminación.
} 
por las empresas, al decir de Briones (1995). El nuevo despido económico objetivo pretendía crear una vía para llevar a cabo el despido por razones económicas de menos del diez por cien de la plantilla - por encima de este tope, debería hacerse a través de un despido colectivo, es decir, de un expediente de regulación de empleo. Sin embargo, en un primer momento su regulación incluía importantes ambigüedades en la propia definición del despido económico, con lo que su aplicación no supuso, entonces, que se mermara la preponderancia del despido disciplinario como vía de ajuste ${ }^{22}$. Este cambio normativo se realizó tras el nunca nacido ni pactado 'Pacto Social'; en efecto, el gobierno del PSOE intentó que la reforma fuera pactada, ya que para hacer frente a la profundidad de la crisis -en 1993 se registró el máximo histórico de despedidos en despidos colectivos- se consideraba que era necesario alterar los costes del despido de los contratos indefinidos. Dado que se trataba de un tema muy sensible para los sindicatos, el Gobierno promovió las conversaciones entre empresarios y sindicatos, pero estas conversaciones fracasaron y el Gobierno impuso directamente la reforma, que, lógicamente, no satisfizo ni a unos ni a $\operatorname{otros}^{23}$.

La reforma del ET de 1997 no ha introducido cambios sobre el despido disciplinario, pero sí que puede afectar a los incentivos para su uso. La reforma de 1997 ha introducido un cambio que va en la línea de alterar los incentivos para usar el despido objetivo por razones económicas, pero sólo para el caso de los nuevos contratos indefinidos. Para éstos la indemnización en caso de improcedencia por despido objetivo económico es de 33 días en lugar de 45, pero sigue siendo de 45 si se trata de un despido disciplinario. En Malo (2000) se presentan comparaciones de ambos sistemas, y la conclusión de dichas comparaciones es que el incentivo para el uso de la vía del despido objetivo económico es reducido, aunque existe. En cualquier caso, esto sólo será relevante para el conjunto de la economía en la medida en que este nuevo tipo de contrato indefinido se extienda, y que, en caso de que se despida a estos trabajadores por razones económicas, realmente se use la vía de las causas económicas. Cabe destacar que esta reforma -lograda durante el primer gobierno del Partido Popular- fue pactada. También en este caso el Gobierno quiso que sindicatos y empresarios llegaran primero a un acuerdo, en lugar de imponer en primer lugar una reforma, ya que parecía existir una extendida sensación de que las limitaciones de la reforma de 1994 se debieron en gran parte a ese nacimiento impuesto tras unas negociaciones infructuosas. Al respecto, nótese cómo el resultado de la negociación parece haber sido la fórmula más simple posible para obtener un resultado negociado, denominada split the difference («partir la diferencia»): la nueva indemnización de improcedencia para los despidos económicos objetivos es prácticamente la media de 20 y 45, el míni-

\footnotetext{
${ }^{22}$ Véase al respecto Malo y Toharia (1999)

${ }^{23}$ Vid. Malo y Toharia (1997).
} 
mo y el máximo de partida de las correspondientes indemnizaciones de procedencia e improcedencia.

Así pues, las sucesivas reformas de los años noventa no han generado un cambio sustancial en el sistema de 1980 del ET, el cual a su vez tampoco modificó la utilización del despido disciplinario improcedente como principal vía para despedir. El modelo de relaciones laborales de la democracia goza de una mayor seguridad jurídica, ya que elimina la posibilidad de que el juez decida la cuantía de la indemnización, que pasa a calcularse mediante una fórmula clara, relacionada con la antigüedad y con el salario, al igual que ha ocurrido con los despidos económicos. No obstante, hay que tener en cuenta que estas cantidades son las que percibe el trabajador en caso de que haya recurrido el despido y no se haya llegado a un acuerdo con anterioridad al juicio en el sindicato vertical -antes de 1975o en las unidades de Mediación, Arbitraje y Conciliación (UMAC) a partir de 1979, o por conciliación de forma previa a la resolución judicial, como puede ocurrir prácticamente en cualquier tipo de litigio. Es decir, estas cantidades no tienen por qué coincidir con las indemnizaciones observadas en todos los casos en ambos sistemas de relaciones laborales, debido a la posibilidad de negociar y pactar una indemnización antes de que el caso llegue a ser resuelto por un juez. En el sistema franquista, la negociación previa en el sindicato vertical era obligatoria ${ }^{24}$.

Con la eliminación del sindicato vertical en 1976, el único acto de negociación era el de conciliación ante el juez. Sin embargo, la gran necesidad de tramitar despidos -generada por la crisis económica- obligó a crear el Instituto de Mediación, Arbitraje y Conciliación a finales de 1979. La situación que permanece desde entonces es de una negociación obligatoria en UMACs -que sustituyeron al Instituto-, otra más ante el juez -el acto de conciliación- y, finalmente, la resolución judicial si no hubiera habido acuerdo en las dos negociaciones anteriores. Como se muestra en el modelo teórico de Malo (2000), este tipo de negociación prejudicial, cuando existen incentivos para usar mayoritariamente la figura del despido disciplinario, conlleva que las indemnizaciones pactadas tenderán a alcanzar la indemnización prevista para el caso de despido improcedente -45 días de salario por año trabajado-, porque, si el caso llegara hasta el juez, éste no tendría más remedio que declararlo improcedente, ya que no se usó propiamente la figura del despido disciplinario -como ocurría bajo la legislación franquista.

\footnotetext{
${ }^{24}$ En un principio, la totalidad del proceso, incluida la conciliación, tenía lugar en la Magistratura de Trabajo. Después, la conciliación se pudo efectuar a través de los Jurados de Empresa (1953) y la Organización Sindical (1958). Siguiendo a Mingo (1994), la conciliación en el sindicato vertical como paso previo a presentar la reclamación ante la Magistratura se vuelve forzosa con la Ley de Procedimiento Laboral de 24 de abril de 1958. No obstante, la conciliación sindical está presente en la legislación desde el Decreto de 9 de enero de 1950 (Ibidem), pero existen datos de conciliación sobre despidos en la Organización Sindical desde 1943, como muestran los datos del Cuadro 2, tomados de García de Blas (1982).
} 
En definitiva, las diferencias entre la dictadura y la democracia en la normativa y la práctica del despido disciplinario son más de detalle que de fondo, ya que ambas se basan en la centralidad del uso desvirtuado del despido disciplinario. No obstante, hay que señalar que, tras la extensión del uso de los contratos temporales -que se ha estancado en torno al 30 por cien de los asalariados desde 1992 y que sólo ha disminuido lentamente desde 1997 en el sector privado-, este sistema de ajuste puede haber ido perdiendo importancia para las empresas, al disponer de la vía de ajuste de los temporales. No obstante, esto depende de si temporales y fijos ocupan el mismo tipo de puestos en las empresas, como defiende Polavieja (2003), o no, como sostienen Malo y Toharia (1999) o Hernanz (2003).

La reforma del desempleo de 2002, impuesta unilateralmente por el gobierno del Partido Popular, sí que introduce cambios sustanciales en dos aspectos del despido: los salarios de tramitación y el pago de la indemnización de improcedencia. En un primer momento, dicha reforma eliminó los salarios de tramitación, pero éstos rápidamente -en realidad, tras las protestas sindicales- han vuelto a entrar en la versión definitiva de la reforma, aunque eliminándose el límite de los dos meses para que la empresa pueda pedir su reembolso a la Administración Pública. Ahora, el trabajador percibe todos los salarios de tramitación, como en los últimos veinte años, pero es un coste totalmente asumido por las empresas. El otro cambio une los salarios de tramitación con la indemnización: si la empresa pone a disposición del trabajador la indemnización de un despido improcedente en los dos días siguientes al despido, el trabajador no tendrá derecho a los salarios de tramitación si recurre el despido y éste finalmente es reconocido como improcedente por el juez. En una situación así, la empresa estaría reconociendo que la causa que alega no es disciplinaria, por lo que está haciendo un despido improcedente, y por esa razón pone a disposición del trabajador la indemnización de improcedencia. Puede apreciarse que el trabajador en esta nueva situación tiene muchos incentivos para aceptar, sea o no verdad la causa alegada, ya que, aunque el despido llegara a ser declarado improcedente por el juez, no se cobraría ninguna cantidad adicional a esos 45 días en concepto de salarios de tramitación. Parece evidente que la consecuencia será que muy pocos despidos llegarán no ya a los juzgados sino siquiera a los organismos de mediación ${ }^{25}$. De esta forma, se fijaría definitivamente el sistema de despido libre costoso -con un coste que, en las comparaciones internacionales de los costes del despido individual, aparece en la actualidad como de los más altos de Euro-

${ }^{25}$ De hecho, los datos de casos de despido tramitados en los servicios de mediación han pasado de ser 285.854 en 2001 y 268.186 en 2002 a 171.024 en 2003 (véase primera columna del Cuadro 1). Este número de despidos tramitados por los servicios de mediación supone un 1,26 por cien del total de asalariados, el valor más bajo de la serie mostrada en el Cuadro 1. Esto, en realidad, significa no que se hagan menos despidos, sino que, tras la reforma de 2002, los datos del servicio de mediación han dejado de ser útiles para medir el total de despidos iniciados, debiendo acudirse en el futuro a otras fuentes complementarias. 
$\mathrm{pa}^{26}$, como se ve en Bertola et al. (1999). Por último, el vaivén de la regulación en los salarios de tramitación entre mayo y octubre de 2002 muestra que no se prescinde de su carácter indemnizatorio, ya que seguirán desempeñando el mismo papel para las finalizaciones ilegales de los contratos temporales.

Finalmente, puede resaltarse de este periodo que los dos principales cambios requirieron apoyo sindical y/o pacto entre los agentes sociales. La reforma de 1984 por la que se generalizaron los contratos temporales contó con el apoyo inicial de UGT, y la reforma de 1997 surgió de un pacto entre sindicatos y empresarios. Este último caso también nos muestra que, lógicamente, es más fácil introducir cambios en la normativa sobre despidos en periodos de expansión que en periodos de crisis -como fue 1994-, ya que durante la expansión las discusiones no se ven afectadas por la perentoria necesidad de ajuste de las empresas ni por las necesidades de cubrir pérdidas de ingresos de los trabajadores despedidos.

\subsection{El sistema de incentivos que ha permitido la dependencia del pasado}

Por último, es inevitable plantearse la siguiente pregunta: ¿Por qué no se ha hecho en algún momento un cambio legal generando una nueva normativa que acabe con este fenómeno de dependencia del pasado? En cierto modo, el ET de 1980 pudo haberse planteado un proceso de creación de una regulación totalmente nueva. Sin embargo, dichos cambios institucionales son muy costosos, y hay que destacar que, en el caso que nos ocupa, están relacionados con la práctica jurídica, más que con la doctrina jurídica, y con los incentivos que genera la normativa, ya que de lo que se trata es de que no se usan para despedir por razones económicas las vías jurídicas existentes para ello. Por tanto, el paso a unas instituciones legales de despido más eficientes tendría que pasar por la creación de un sistema de incentivos adecuado para reconducir el uso de las diferentes categorías existentes para despedir ${ }^{27}$.

${ }^{26}$ Una cuestión que, hasta donde conozco, no ha sido analizada es si durante todo el periodo analizado, desde los años cuarenta hasta la actualidad, realmente España ha estado en esa posición relativa respecto a otros países europeos. No obstante, cabe señalar que la aprobación del Estatuto de los Trabajadores supuso un descenso de las indemnizaciones máximas en caso de despido, y que las sucesivas reformas de los años noventa han pretendido rebajar dichas indemnizaciones máximas para el caso del despido económico objetivo.

${ }^{27} \mathrm{La}$ falta de eficiencia a la que nos referimos consiste en que la norma legal no sirve para el fin que se pretende que tenga, tanto en términos jurídicos -control de la causa de despidocomo económicos -que el despido económico procedente tenga un coste, y el despido disciplinario improcedente tenga un coste superior. Además, se desvirtúa la utilización de las causas para despedir, lo cual puede generar indefensión jurídica para los trabajadores y un perjuicio para la protección de sus derechos laborales, es decir, un entorno con mayor incertidumbre para los trabajadores. Esta normativa es eficaz para conseguir una serie de objetivos -los beneficios que el sistema tiene para las partes y que describiremos a continuación-, pero lo hace con unos costes nada despreciables. 
Analicemos ahora qué beneficios obtiene cada parte de las relaciones laborales con este sistema de despido: gobierno, empresas y trabajadores.

¿Qué beneficios tuvo que obtener el gobierno franquista que instauró tal sistema y los gobiernos democráticos que no lo han eliminado? Este sistema produce una ralentización de los procesos de ajuste de plantilla ante los shocks negativos, ya que lo que tomaría la forma de un despido colectivo visible socialmente pasa a convertirse en una sucesión de despidos individuales. Este sistema es viable gracias a la existencia de otro mecanismo para los ajustes de plantilla que no pueden ser ralentizados: los expedientes de crisis en el franquismo y los expedientes de regulación de empleo con el ET. Esta individualización y ralentización resultaban especialmente útiles para el gobierno franquista a finales de los años cincuenta, cuando el anquilosamiento de la economía autárquica estaba generando considerables tensiones sociales. Pero los gobiernos democráticos obtienen el mismo tipo de beneficio de este sistema de despido, ya que evita su propia implicación en los procesos de ajuste de plantilla, y las oscilaciones del desempleo podrían suavizarse gracias a que se produciría un goteo de despidos en lugar de entradas masivas cuando se produce un shock negativo -salvo cuando la urgencia del ajuste es tal que el despido colectivo resulta inevitable.

Las empresas se benefician de la individualización y ralentización de los procesos de ajuste, lo cual da la posibilidad de aprovechar la heterogeneidad de los trabajadores para disminuir los costes en relación con una negociación con todos los trabajadores que se van a despedir como colectivo, minimizando así la posibilidad de que el ajuste se vea acompañado de huelgas, paros, intervención de la Administración Pública, etc. Obviamente, también ganan en discrecionalidad: no en vano este sistema les permite despedir a quien deseen, aunque asumiendo un coste positivo, siendo dicho coste la verdadera limitación a esa libre disposición de los trabajadores.

Los trabajadores se benefician de este sistema de despido porque perciben 45 días de salario por año trabajado en lugar de los 20 que corresponderían a un uso de las causas de despido estrictamente legal, por ser esta última la indemnización correspondiente al despido económico procedente. Esta más que duplicación de la indemnización es lo que probablemente previene a los sindicatos durante la democracia de abogar por la reforma completa del sistema para un uso no desvirtuado de las causas para despedir. Es muy probable que, al aprobarse el ET en un momento de drásticas reducciones de plantilla -y de quiebras-, los sindicatos no vieran como apropiado embarcarse en intentar una reforma completa del sistema de despido que introdujera incentivos para un uso apropiado de las causas económicas, porque probablemente la indemnización habría tenido que ser más baja (20 días), y no se olvide que el sistema de despido libre costoso incentiva el ajuste paulatino en lugar del masivo y repentino, algo que en principio parece razonable que prefieran los representantes de los trabajadores $-\mathrm{y}$ los trabajadores mismos. 
Este sistema de despido genera desventajas, tanto de tipo privado como público. Las desventajas privadas se concentran en las empresas, que más que doblan el coste de los despidos económicos, pero también las sufren los trabajadores en términos de la inseguridad jurídica que genera un sistema que, de hecho, no es capaz de conseguir un uso apropiado de las causas para despedir.

En cuanto a las desventajas públicas tendríamos la generación de costes burocráticos -que tienen efectos macroeconómicos negativos, como muestra Burda (1992) - y la judicialización de los despidos. Tanto los costes burocráticos como los de judicialización podrían haberse reducido notablemente por los incentivos generados por la reforma de las prestaciones de desempleo de 2002, al crear fuertes incentivos para que los despidos se resuelvan en apenas dos días poniendo a disposición del trabajador la indemnización de improcedencia. Se fija, no obstante, con dicha reforma que, de facto, el verdadero coste del despido económico alcance los 45 días de salario por año de antigüedad en lugar de los 20 previstos en la propia ley -punto desarrollado por Malo (2000)-, y se vacíe la figura jurídica del despido económico, salvo en los casos en que los ajustes no pueden ralentizarse $^{28}$. Por otro lado, al ser un sistema que propicia el goteo de despidos -recuérdese que incentiva el uso de los despidos individuales frente a los colectivos-, no es adecuado para el ajuste frente a grandes shocks inesperados -como los sufridos por la economía mundial en los setenta-, y desincentiva la reestructuración de los sectores económicos no competitivos. De ahí que la normativa, ya en el periodo de la Transición y de la democracia desbordara en cierto sentido dicho sistema, tratando de generalizar el recurso a los contratos temporales -desde 1984- y renovando la normativa de los despidos colectivos - con el ET de 1980y, más tarde, con la introducción de los despidos económicos objetivos, rudimentariamente en 1977 y con total claridad en 1994.

En conclusión, la ineficiencia de este sistema de despido libre costoso se plasma en más que doblar el coste que las empresas deben soportar para la realización de despidos realmente económicos, en las relativas dificultades que plantea para la realización de ajustes rápidos frente a situaciones económicas negativas generalizadas, y en la desvirtuación añadida de las causas para despedir previstas en la letra de la normativa, que genera indefensión jurídica para los trabajadores, coste que asumen a cambio de indemnizaciones más altas. Dado que los políticos del gobierno puede entenderse como una parte más que experimenta costes y beneficios debido al sistema de despido -sobre todo en términos electorales tras la

${ }^{28}$ Con todo, si este sistema introducido en 2002 se mantiene y el contrato indefinido con indemnización de improcedencia de 33 días para los despidos económicos se generaliza, es posible que, con el tiempo, el coste del despido para las empresas disminuya. En el momento actual se carece de información que pueda avalar esta eventual evolución futura. A pesar de todo, nótese que se pasaría a tomar como referencia los 33 días y no los 20 que, desde 1980, es lo que la ley quiso fijar como indemnización para los despidos económicos. 
instauración del sistema democrático-, se produce una dificultad adicional, y es que esto le dificulta realizar el papel de internalizador de las externalidades que tradicionalmente se atribuye al gobierno en buena parte de los modelos macroeconómicos. Esto supone una limitación adicional para generar un cambio normativo que pudiera superar los problemas que ocasiona un sistema de despido libre costoso como el español, introducido a través de un accidente histórico y mantenido y desarrollado por los incentivos de empresarios, trabajadores y políticos.

\section{CONCLUSIONES}

En este artículo se ha mostrado que la evolución histórica del despido disciplinario en España ha permitido a la práctica jurídica buscar los resquicios normativos para que el empresario pueda disfrutar de la posibilidad de despedir sin causa cuando necesita reducir la plantilla por razones económicas, si bien asumiendo unas indemnizaciones más elevadas que las que se pagarían si se siguiera el proceso establecido para las razones económicas. Esto se produce porque los agentes económicos no son pasivos ante la legislación, sino que la usan estratégicamente para alcanzar sus propios fines: la empresa para despedir cuando convenga a su actividad económica, el trabajador para cubrir las eventuales pérdidas de ingresos derivadas del despido, y el Gobierno para minimizar los problemas de apoyo social que generan los aumentos de despidos y del paro durante las crisis.

La interpretación económica que se ha realizado de los cambios normativos constituye una aportación al conocimiento de la regulación del mercado de trabajo, porque explica la forma en que aparece este sistema de despido libre costoso en España: a través de la introducción de cambios que tenían otra motivación en su momento histórico. Un cambio aparentemente pequeño, como fue el incidente de no readmisión, y debido a un accidente histórico -las necesidades del fosilizado sistema económico autárquico del primer franquismo-, pervive una vez desaparecida la razón histórica de su aparición y se vuelve un componente crucial del sistema clásico de despido, debido a los incentivos que el gobierno franquista tenía para mantenerlo, resumibles en individualización de los conflictos y ralentización de los despidos. Esto habría generado un fenómeno de dependencia del pasado como los señalados por North (1990): la historia de las instituciones importa, porque los pequeños cambios del pasado son cruciales para entender los cambios que hoy en día tienen incentivos para introducir los reformadores -en este caso, en la normativa legal del despido.

La comprensión de las razones históricas de nuestras leyes sobre despido y de los incentivos que generan para las distintas partes del sistema de relaciones laborales nos permite entender mejor el último cambio de nuestra legislación sobre despido. La reforma de las prestaciones por desempleo de 2002 permite que el 
despido tenga plenos efectos -sobre todo, para el cobro de prestaciones por desempleo- si en los dos días posteriores al despido el empresario pone a disposición del trabajador la indemnización por despido improcedente. Desde la perspectiva de este trabajo, se trata de la consagración definitiva del sistema español de despido libre pero costoso, marcándose el coste con la indemnización del despido improcedente, superior a la prevista en el ET para el despido económico procedente. Es como si el intento de extender de nuevo la contratación indefinida y reducir la temporal fuera acompañado de la introducción de una nueva facilidad para despedir de las empresas, pero siguiendo el camino históricamente marcado de la escasa o nula importancia práctica de las causas para despedir. En definitiva, se mantiene el problema de una normativa legal sobre un aspecto clave de la vida económica -el despido- eliminando de hecho el control de la causa del despido -con la consiguiente indefensión jurídica del trabajador-, y el incremento de la indemnización en los despidos económicos con respecto a los 20 días de salario por año de antigüedad, dificultando el ajuste frente a los grandes shocks negativos y la reestructuración de sectores no competitivos.

¿Cabe esperar algún tipo de gran modificación en un futuro próximo? Si el argumento presentado aquí es correcto, la respuesta ha de ser negativa, ya que los representantes de los trabajadores serán reticentes a aceptar una rebaja de las indemnizaciones realmente percibidas por los trabajadores, las empresas serán reacias a renunciar a la libertad para despedir que otorga este sistema de despido, y los políticos tendrán escasos incentivos para introducir por su propio pie un nuevo marco legal hacia un sistema de despido que no genere los problemas anteriores, porque dejaría de promoverse el goteo de despidos en favor de mayores ajustes de plantilla.

\section{BIBLIOGRAFÍA}

Alchian, A. (1950): «Uncertainty, Evolution and Economic Theory». Journal of Political Economy 58, pp. 211-221.

Alonso, M. (1970): «La ejecución de las sentencias de despido: el incidente de no readmisión». Revista de Política Social 87, pp. 55-75.

Almansa, J. M. (1968): El despido nulo. Madrid: Tecnos.

BABIANo, J. (1995): Emigrantes, cronómetros y huelgas. Un estudio sobre el trabajo y los trabajadores durante el franquismo (Madrid, 1951-1977). Madrid: Siglo XXI de España Editores.

- (1998): Paternalismo industrial y disciplina fabril en España (1938-1958). Madrid: Consejo Económico y Social.

Bertola, G., Boeri, T. y Cazes, S. (1999): «Employment protection and labour market adjustment in OECD countries: Evolving institutions and variable enforcement», 
Employment and Training Papers 48, International Labour Office (disponible en Internet: http://www.ilo.org/public/english/employment/strat/publ/etp48.htm; último acceso 14/ 09/2003).

BRIONES, C. (1995): La extinción del contrato de trabajo por causas objetivas. Madrid: Ministerio de Trabajo y Seguridad Social.

Burda, M. C. (1992): «A Note on Firing Costs and Severance Benefits in Equilibrium Unemployment». Scandinavian Journal of Economics 94 (3), pp. 489-489.

Cazorla, A. (2000): Las políticas de la victoria. La consolidación del Nuevo Estado franquista (1938-1953). Madrid: Marcial Pons.

DAvid, P. (1985): «Clio and the Economics of QWERTY». American Economic Review 75, pp. 332-337.

Del Valle, J. M. (1996): La extinción del contrato de trabajo por causas económicas, técnicas, organizativas y de producción. Madrid: Ediciones ACARL.

FinA, L., Meixide, A. y Toharia, L. (1989): «Reregulating the Labor Market amid an Economic and Political Crisis: 1975-1986», en S. Rosenberg (ed.), The State and the Labor Market. Nueva York: Plenum Press, pp. 107-125.

GARCía DE BLAs, L. (1982): «Una medición del coste de ajuste de plantillas en España», en El mercado de trabajo en España. Madrid: Ministerio de Economía, pp. 185-237.

Hernanz, V. (2003): El trabajo temporal y la segmentación. Madrid: Consejo Económico y Social.

Ichino, A., Polo, M. y Rettore, E. (2003): «Are Judges Biased by Labor Market Conditions?». European Economic Review 47 (5), pp. 913-944.

Instiuto Nacional de Estadística (1964 ...): Encuesta(s) de Población Activa. Madrid.

- (1954 ...): Contabilidad Nacional de España. Madrid.

JiMENo, J. F. y TOHARIA, L. (1993): «El despido y sus costes: ¿qué reformas?», Economistas 55, pp. 243-255.

Malo, M. A. (1998): Las indemnizaciones por despido: un problema de negociación. Madrid: Ediciones ACARL.

- (2000): «A simple model of severance pay determination: the case of individual dismissals in Spain». Labour 14, pp. 269-290.

Malo, M. A. y Toharia, L. (1997): «Economía y Derecho del Trabajo: las reformas laborales de 1994 y 1997». Cuadernos Económicos de ICE 63, pp.155-174.

- (1999): Costes de despido y creación de empleo. Madrid: Ministerio de Trabajo y Asuntos Sociales.

Malo de Molina, J. L. (1983): «El impacto del cambio institucional en el mercado de trabajo durante la crisis», Papeles de Economía Española 15 , pp. 239-257.

- (1984): «Distorsión y ajuste del mercado de trabajo español». Papeles de Economía Española 21 , pp. 214-235.

Mingo, J. A. (1994): «La conflictividad individual en Madrid bajo el franquismo (194075)», en AA.VV., Clase obrera, conflicto laboral y representación laboral (evaluación socio-laboral de Madrid, 1939-1991). Madrid: Ediciones GPS-Madrid, pp. 123-163.

Ministerio de Trabajo y Seguridad Social (1983...): Boletín de Estadísticas Laborales. Madrid.

Molinero, C. e Ysàs, P. (1998): Productores disciplinados y minorías subversivas. Clase obrera y conflictividad laboral en la España franquista. Madrid: Siglo XXI de España Editores. 
Montoya, A. (1978): «La estabilidad en el empleo en el Derecho del Trabajo de España». Revista de Política Social 18, pp. 45-68.

NorTH, D. (1990): Institutions, Institutional Change and Economic Performance. Cambridge: Cambridge University Press.

Ortiz, M. C. (1995): La ejecución de sentencias de despido. Madrid: Ediciones ACARL.

Polavieja, J. (2003): Estables y Precarios (Desregulación Laboral y Estratificación Social en España). Madrid: CIS.

Prados de la Escosura, L. (2003): El Progreso Económico de España (1850-2000). Bilbao: Fundación BBVA.

Preston, P. (1987): La destrucción de la Democracia en España. Reforma, reacción y revolución en la II República. Madrid: Alianza Editorial.

Rivero, J. (1966): «Estabilidad en el empleo en el Ordenamiento Laboral español». Revista de Política Social 70, pp. 197-214.

- (1970): «La conciliación judicial en los procesos laborales». Revista de Política Social 85, pp. 143-178.

RodríGUEZ FERnÁndez, M. L. (1989): El incidente de no readmisión. Madrid: Ministerio de Justicia.

Serrano, A. y Malo de Molina, J. L. (1979): Salarios y mercado de trabajo en España. Madrid: H. Blume Ediciones.

Sото, A. (1996): «Conflictividad social y transición sindical», en J. Tusell y A. Soto (eds.), Historia de la transición, 1975-1986. Madrid: Alianza Universidad, pp. 363-408.

- (2003): «Rupturas y continuidades en las relaciones laborales del primer franquismo, 1938-1958», en C. Barciela (ed.), Autarquía y Mercado Negro. Barcelona: Editorial Crítica, pp. 217-245.

Toharia, L. y Malo M. A. (1994): «Los costes del despido en España». Revista de Economía y Sociología del Trabajo 25-26 (septiembre-diciembre), pp. 180-192.

Tuñón, M. (1976): La II República. Madrid: Siglo XXI de España Editores, volúmenes I y II.

VALDÉs, F. (1985): «Flexibilidad en el mercado de trabajo y ordenamiento laboral». Papeles de Economía Española 22, pp. 302-315. 
